\title{
Interculturalidade e conhecimento tradicional sobre a Lua na formação de professores no/do campo
}

\author{
Rodrigo dos Santos Crepalde ${ }^{1}$, Verônica Klepka², Tânia Halley Oliveira Pinto ${ }^{3}$ \\ ${ }^{1}$ Universidade Federal do Triângulo Mineiro - UFTM. Departamento de Educação em Ciências, Matemática e \\ Tecnologias do Instituto de Ciências Exatas, Naturais e Educação. Avenida Randolfo Borges Júnior, 1400. \\ Univerdecidade. Uberaba - MG. Brasil. rodrigocrepalde@gmail.com. ${ }^{2}$ Universidade Federal do Triângulo \\ Mineiro - UFTM. ${ }^{3}$ Universidade Federal do Triângulo Mineiro - UFTM.
}

RESUMO. O tratamento dado ao conhecimento tradicional pela ciência escolar tende a desvalorizá-lo, submetendo-o à visão ingênua, de senso comum, e até mitológica. Como forma de promover o diálogo e a troca entre culturas diferentes, que povoam a sala de aula, a interculturalidade assume que o Ensino de Ciências deve ser considerado como a aquisição de mais uma cultura, sem para isso sobrepor a validade das outras. Este artigo apresenta um caso concreto de ensino e aprendizagem, das ciências físicas, como exemplo da promoção do reconhecimento do conhecimento tradicional sobre a Lua em um contexto de formação intercultural de professores para o campo. São discutidos trechos representativos de produções escritas de licenciandos em Educação do Campo, habilitação Ciências da Natureza, realizadas na disciplina de Introdução à Física que tiveram como objetivo argumentar sobre o modo como os conhecimentos científico e tradicional estão relacionados à Lua e as suas implicações para o Ensino de Ciências. Nota-se que o conhecimento tradicional está fortemente entrelaçado às práticas sociais de comunidades desses licenciandos, apontando a necessária inclusão desse conhecimento na formação intercultural de professores para o campo que estimule o intercâmbio e o enriquecimento mútuo.

Palavras-chave: Conhecimento Tradicional, Educação Intercultural em Ciências, Formação de Professores para o Campo. 


\title{
Interculturallity and traditional knowledge about the moon in teacher training at the/of rural education
}

\begin{abstract}
The treatment given to traditional knowledge by school science tends to devalue it, subjecting it to naive, common sense, and even mythological vision. As a way of promoting dialogue and exchange between different cultures, which populate the classroom, interculturallity assumes that science education should be considered as the acquisition of yet another culture, without overcoming the validity of the others. This article presents a concrete case of teaching and learning of the physical sciences as an example of promoting the recognition of traditional knowledge about the Moon in a context of intercultural rural science teacher education. They are discussed representative excerpts of written productions of undergraduate rural education, major in natural sciences, conducted in the discipline of Introduction to Physics that aimed to argue about how scientific and traditional knowledge are related to the Moon and its implications for science teaching. It is noted that traditional knowledge is strongly intertwined with the social practices of communities of these graduates, pointing out the necessary inclusion of this knowledge in the intercultural rural science teacher education that stimulates the exchange and mutual enrichment.
\end{abstract}

Keywords: Traditional Knowledge, Intercultural Science Education, Rural Science Teacher Education. 


\section{Interculturalidad y el conocimiento tradicional sobre la Luna en la formación docente en/del campo}

RESUMEN: El tratamiento dado al conocimiento tradicional por la ciencia escolar tiende a desvalorizarlo, sometiéndolo a la visión ingenua, de sentido común, y hasta mitológica. Con el fin de promover el diálogo y el intercambio entre las diferentes culturas que pueblan el aula, la interculturalidad asume que la enseñanza de las ciencias debe ser considerada como la adquisición de otra cultura sin para ello sobreponer la validez de las otras. En este artículo se presenta un caso de la enseñanza y el aprendizaje, de las ciencias físicas, como un ejemplo de la promoción del reconocimiento de los conocimientos tradicionales acerca de la Luna en un contexto de formación intercultural de los maestros para el campo. Se discuten fragmentos representativos de producciones escritas de estudiantes de graduación en educación del campo, habilitación ciencias de la naturaleza, realizadas en la disciplina de Introducción a la Física que tuvieron como objetivo argumentar sobre el modo como los conocimientos científico y tradicional están relacionados a la Luna y sus implicaciones para la enseñanza de las ciencias. Se observa que el conocimiento tradicional está fuertemente entrelazado a las prácticas sociales de comunidades de esos estudiantes de graduación, señalando la necesaria inclusión de este conocimiento en la formación intercultural de los maestros para el campo que estimula el intercambio y enriquecimiento mutuo.

Palabras clave: Conocimiento Tradicional, Educación Intercultural en Ciencias, Formación de Maestros para el Campo. 


\section{Introdução}

Nas últimas décadas, os movimentos sociais enquanto sujeitos de direitos a terra, ao território, à igualdade e às diferenças, têm pressionado para que suas experiências e saberes sejam reconhecidos como conhecimento legítimo. Lutam, além disso, para terem direito e acesso a bens culturais e materiais, historicamente apropriados por poucos na sociedade hierarquizada e desigual em que vivemos. Desse modo, os movimentos do campo, articulados com a luta pela reforma agrária, incorporaram a seus discursos e a suas pautas de reivindicações a luta pela educação. Nesse sentido, a abertura de cursos específicos para formar docentes e educadores dos diversos coletivos sociais, étnicos, raciais e geracionais, e do campo, faz parte de uma realidade recente em várias universidades do Brasil (Arroyo, 2008, 2011; AntunesRocha, 2009).

A tentativa de incorporar os saberes e as experiências como conhecimentos legítimos dos novos coletivos que chegam à escola e à universidade exibe uma tendência de considerá-los como saberes prévios, brutos e pré-científicos. Isto é, parte de um olhar piedoso, populista, superficial e etnocêntrico que subestima o valor da experiência e do conhecimento produzido na riqueza e diversidade da vida social (Arroyo, 2008).

Se os coletivos que chegam à universidade têm o direito de ouvir e aprender as concepções, conhecimentos, significados da realidade acumulados no ensino, na pesquisa, na reflexão teórica organizada, a universidade, por sua parte, tem o direito e o dever de ouvir, aprender as concepções, vivências, culturas, valores, conhecimentos, formas de entenderse e entender o real e a rica vivência da diversidade vinda desses coletivos. Sobretudo, de sua história de segregação e silenciamento, que também é um espaço de produção de conhecimento e de valores. (Arroyo, 2008, p. 31).

Como sustenta Santos (2009) a injustiça social global possui ligações íntimas com a injustiça cognitiva global e, em resposta, a resistência política deve assumir a resistência epistemológica. Para tanto, o autor defende a ideia do cosmopolitismo subalterno, forma política e cultural da globalização contra hegemônicai.

A novidade do cosmopolitismo subalterno reside, acima de tudo, em ter um profundo sentido de incompletude, sem, contudo, ambicionar a completude. Por um lado, defende que a compreensão do mundo excede largamente a compreensão ocidental do mundo e, portanto, a nossa compreensão da globalização é muito menos global que a própria globalização. Por outro lado, defende que quanto mais compreensões não-ocidentais forem identificadas mais evidente se tornará 
o facto de que muitas outras continuam por identificar e que as compreensões híbridas, que misturam componentes ocidentais e nãoocidentais, são virtualmente infinitas. (Santos, 2009, p. 43).

Nessa direção, a ecologia de saberes afirma-se como alternativa à monocultura da ciência moderna: "é uma ecologia porque se baseia no reconhecimento da pluralidade de conhecimentos heterogêneos (sendo um deles a ciência moderna) e em interações sustentáveis e dinâmicas entre eles sem comprometer sua autonomia" (Santos, 2009, p. 44-45). Se há uma epistemologia geral que governa a ecologia de saberes, ela toma como pressuposto a impossibilidade de uma epistemologia geral - o conhecimento é entendido como interconhecimento. Assim, o reconhecimento da diversidade cultural passa, necessariamente, pelo reconhecimento da diversidade epistemológica do mundo (Santos, 2009).

Nesse contexto, a formação de professores de ciências para o campo não pode ficar subsumida aos conhecimentos canônicos da ciência escolar sob pena de silenciar e colocar em segundo plano a cultura e as práticas sociais camponesas. Essa afirmação parece mera redundância, pois estamos tratando de novos sujeitos que chegam à universidade e, portanto, exigem, por direito, novas pedagogias. No entanto, a articulação entre a pesquisa e prática pedagógica em Ensino de Ciências e a área da Educação do Campo ainda é recente.

O comprometimento com os princípios da Educação do Campo implica também a articulação das ciências para compreensão profunda de temas como "soberania alimentar e nutricional", "desenvolvimento sustentável", "agroecologia vs biotecnologia", dentre outros que necessitem da articulação com áreas do conhecimento que se debruçam sobre os problemas presentes nos diversos contexto do campo. Isso implica a necessidade de articulação com disciplinas de outras áreas do conhecimento (Ciências Agrárias, Antropologia, Psicologia, Geografia, Saúde) em suas atividades de pesquisa e/ou extensão, para contribuir com os estudos que permitam um olhar mais complexo para a realidade local, propiciando também o substrato para análises do ponto de vista das ciências que sejam engajadas e comprometidas com as demandas locais. (Brick et al., 2014, p. 45-46).

Nesse sentido, este trabalho se insere num programa mais amplo de pesquisa que pretende compreender as relações entre os conhecimentos tradicional e científico que emergem de práticas sociais do campo, bem como caracterizar suas contribuições para formação de professores em uma perspectiva intercultural em ciências. A partir desse propósito mais amplo, algumas questões orientam esse programa de investigação: i) de que modo os conhecimentos científico e tradicional constroem pontos de aproximação e 
afastamento no contexto de formação de professores para o campo?; ii) por meio de quais estratégias didáticas ocorre a afirmação e não o silenciamento dos conhecimentos tradicionais do campo?; iii) quais são as implicações para a formação de professores do campo quando o conhecimento tradicional passa a constituir-se como discurso objeto de ensino e aprendizagem da ciência escolar?

O texto que apresentamos por agora possui dois propósitos: um primeiro, de ordem teórica, afirmar a necessidade da formação de professores de ciências coerente e responsável ${ }^{\mathrm{ii}}$ com a vida no/do campo. Do nosso ponto de vista, não basta apenas "selecionar" algumas ideias chave das ciências naturais que dialoguem em maior medida com a vida e luta das populações do campo, mas também é preciso questionar os conteúdos canônicos das Ciências Naturais incorporando o conhecimento tradicional como meta do Ensino de Ciências e como um dos discursos que podem constituir a ciência escolar. O segundo propósito, de natureza mais empírica, consiste em traduzir em um caso concreto de ensino e aprendizagem, das Ciências Físicas, a promoção do reconhecimento do conhecimento tradicional sobre a Lua em um contexto de formação intercultural de professores para o campo.
A construção deste trabalho foi motivada pela experiência do primeiro autor como docente em um curso de Licenciatura em Educação do Campo (LECampo) da Universidade Federal do Triângulo Mineiro (UFTM), localizada no estado de Minas Gerais e das pesquisas que tem realizado desde o mestrado no âmbito da educação intercultural em ciências. De modo particular, a temática da Lua emergiu de uma proposta de trabalho final da disciplina Introdução à Física do curso mencionado que teve como objetivo a pesquisa sobre o modo como os conhecimentos científico e tradicional estão relacionados à Lua e as suas implicações para o Ensino de Ciências. A temática "Lua" não foi uma escolha arbitrária, mas, decorrente do arcabouço prático de vida dos estudantes da LECampo desta universidade. De modo que, o uso da Lua como um artefato cultural para explicar fenômenos perpassou e perpassa outras disciplinas e contextos educativos do curso. Isso foi mote para que os autores deste artigo convergissem seus esforços em desenvolver projetos e atividades de ensino de maneira interdisciplinar, promovendo a discussão intercultural, voltada para a formação inicial e continuada de professores do campo, tomando como base algumas práticas sociais emergentes do contexto 
dos alunos do curso. Nesse sentido, cursos formativos e projetos de iniciação científica, pesquisa e extensão estão sendo realizados envolvendo a interculturalidade junto aos temas Lua, Etnobotânica e Biofertilizantes como eixos a serem dialogados no Ensino de Ciências.

\section{Interculturalidade e formação de professores do campo}

Tende-se a considerar que no mundo atual tornou-se imprescindível a comunicação entre as diferentes culturas dados os inúmeros conflitos sociais existentes e a complexificação destes. Entretanto, é interessante notar o que está implícito nesta demanda. Esconde-se nessa frase o fato de que, por séculos, os diferentes povos e suas culturas foram silenciados em detrimento de um monólogo, o do dominador, personificado de várias maneiras, seja por meio do colonizador que invadiu uma terra $\mathrm{e}$ obrigou aos nativos o culto a seus deuses e uso de sua linguagem, símbolos e vestimentas, seja daquele que desqualifica formas diferentes de ver o mundo, estabelecendo um padrão de verdade, como tem feito historicamente a ciência ocidental. Trata-se do localismo globalizado que denomina Santos (2003), um tipo de globalização que cultua a hegemonia e, assim, a assimetria nas relações. Portanto, não de hoje, os movimentos sociais conquistaram, nas últimas décadas, políticas públicas que os permitiram seguir suas lutas e alcançar legitimidade. Em resposta a isso, teorias e estudos foram se voltando a compreender essa dinâmica demonstrando a incompletude das culturas, já que "nenhuma forma singular de conhecimento pode responder por todas as intervenções possíveis no mundo, todas elas são, de diferentes maneiras, incompletas". (Santos, 2009, p. 49). É nesta última perspectiva que surge a interculturalidade.

O conceito de interculturalidade assume múltiplas caracterizações, mas, de modo geral, "traz a ideia de inter-relação, diálogo e troca entre culturas diferentes e supõe a coexistência da diversidade como riqueza" (Paladino \& Almeida, 2012, p. 16), ou seja, um tratamento igualitário das culturas sem sobreposições. A interculturalidade pressupõe a existências de múltiplas formas de culturas que convivem juntas, o que nos proporciona a diversidade. A interculturalidade, nesse sentido, promove o empoderamento de culturas historicamente homogeneizadas, diluídas, apagadas pela globalização (Fleuri, 2003; Paladino \& Almeida, 2012; Candau, 2013) como é o caso das práticas sociais dos povos do campo. 
Com a conquista pelo direito à educação, os povos do campo requerem também, por legítimo direito, o reconhecimento de seus saberes como formas explicativas do mundo no qual vivem e trabalham, de modo que o Ensino de Ciências voltado a esses sujeitos necessariamente passa por cruzamentos culturais possibilitando o "aprender ciência enquanto aquisição de cultura" (Aikenhead, 2009, p. 90, destaque no original) e não sobreposição da visão da ciência sobre a sua própria visão de mundo. Assim, o Ensino de Ciências numa perspectiva intercultural implica que o papel do professor, seja ele do campo ou não, é basicamente: i) questionar o etnocentrismo e assumir uma atitude de estranhamento e relativização a fim de perceber outras culturas que não a sua própria; ii) promover um diálogo que possibilite que o aluno traga seus conhecimentos, repertório cultural simbólico, etc., para o diálogo na sala de aula sem que estes sejam desvalorizados; iii) demarcar fronteiras que possibilitem o reconhecimento de qual cultura está se falando; iv) promover o cruzamento dessas fronteiras reconhecendo nas diferentes culturas pontos convergentes e divergentes sobre a explicação de um dado fenômeno natural; e, v) oportunizar que a cultura do aluno emerja sendo também objeto da ciência escolar.

A educação, e, consequentemente, a formação intercultural de professores de ciências para o campo, pressupõe:

\begin{abstract}
... adotar a perspectiva do intercultural como processo de diálogo, comunicação entre pessoas ou grupos pertencentes a culturas diferentes (nacionalidades, origem social, gênero, ocupação, etc.), que promove a integração e o respeito à diversidade e permite ao educando encontrar-se com a cultura do outro sem deixar de lado a sua própria, ou seja, incentiva o respeito a outras culturas, a superação de preconceitos culturais e do etnocentrismo. (Walesko, 2006, p. 27).
\end{abstract}

Foroni (2004, p. 83) destaca que,

O principal desafio da prática pedagógica intercultural torna-se a necessidade de elaborar a multiplicidade e a contraditoriedade de modelos culturais que interferem na formação de visão de mundo dos educandos e compreender as relações que tal visão estabelece com os "modelos" transmitidos por meio de situações educativas vividas, particularmente, na escola.

Em outras palavras, para que o professor possa reconhecer a multiplicidade das culturas é preciso que seja ensinado a realizar essa elaboração. A formação de professores na perspectiva intercultural torna-se, portanto, inerente ao currículo. É por meio dessa formação intercultural que pode haver a mudança de 
uma prática voltada à "transmissão de uma cultura homogênea e coesa para a elaboração de uma diversidade de modelos culturais que interagem na formação dos educandos" (Foroni, 2004, p. 83). Uma prática que sustente um projeto de educação integrador e interdisciplinar.

Foroni (2004, p. 85) completa que, ao perceberem o reconhecimento de seus modos de vida, símbolos, manifestações e comportamentos culturais pelos professores e nos professores, os estudantes constroem uma autoestima que gera "confiança e predisposição para a aquisição de outros saberes". Efetiva-se a possibilidade de cruzamentos culturais. Quando isso não ocorre,

a perspectiva de uma formação monocultural do aluno futuroprofessor, a valorização de uma cultura única e as práticas de homogeneidade social, regidas por princípios que orientam a assimilação ou homogeneização cultural da formação, apontam para o caráter injusto e empobrecedor da "pseudoinclusão" desses novos grupos, principalmente quando se pensa na posterior atividade docente desses alunos em seus grupos societais. Ao se silenciar a "fala da diversidade e da identidade cultural" com a imposição de um pacote único e fechado, composto de conteúdos "pré-fixados e hegemônicos", estaremos arriscados a transportar para suas futuras práticas educativas a reprodução e fixação de modelos que não lhes sejam compatíveis. (Foroni, 2004, p. 85).
Essa incompatibilidade de modelos explicativos, irrelevantes e inatingíveis para uma dada cultura é resultado da imposição de uma "cultura estrangeira" para o aluno, a da ciência (Aikenhead, 2009). Portanto, a formação intercultural de professores do campo e para o campo deve considerar os saberes que esses alunos trazem da sua cultura, mas não basta apenas considerá-los, é preciso entendê-los e integrá-los aos conteúdos, uma ação que só é possível a partir de projetos que busquem compreender quais são as culturas presentes em uma sala de aula, de onde partem esses sujeitos e para onde retornarão.

\section{Conhecimento tradicional: alguns apontamentos}

Nesse trabalho optamos pelo emprego da palavra conhecimento ao invés de saberii por entender que o primeiro é mais restrito e contextual tal como discurso, assumido por nós em uma perspectiva bakhtiniana: “... o discurso, ou seja, a língua em sua integridade concreta e viva, e não a língua como objeto específico da linguística, obtido por meio de uma abstração absolutamente legítima e necessária de alguns aspectos da vida concreta do discurso" (Bakhtin, 2010, p. 181). Nesse sentido, o discurso é formado por diversas vozes (posições sociais, 
pontos de vista); responde a outros dizeres; possui uma história; manifesta-se como enunciados concretos de determinados falantes. Em outras palavras, o discurso é constitutivamente dialógico, ideológico e histórico (Flores et al., 2009).

Chamamos de conhecimento tradicional o discurso (re)produzido/ recontextualizado ${ }^{\text {iv }}$ por práticas sociais que têm sua gênese na tradição e luta populares, comumente transmitido pela oralidade e predominantemente organizado pelo modo narrativo. Aqui não incluiremos os conhecimentos das populações indígenas, apesar da relação inequívoca e entrelaçada entre eles. Esse destaque cumpre um duplo propósito em nosso texto: i) não temos ou desenvolvemos elementos do ponto de vista teórico e empírico para adentrar no universo das epistemologias e práticas sociais indígenas, mas não prescindimos de trabalhos dentro dessa temática que possam por analogia, similaridade ou extensão dos argumentos auxiliarem nossa reflexão; ii) há uma distinção do ponto de vista antropológico e legal entre populações tradicionais e indígenas, mesmo levando em conta que as primeiras tomam em diversas situações as primeiras como modelo (Carneiro da Cunha \& Almeida, 2009).

O tradicional a que nos referimos não é necessariamente antigo, tampouco é estável, alheio a mudanças e somente reconhecido em práticas em desuso. O conhecimento tradicional possui sua contemporaneidade, pois continua sendo produzido, experimentado e compartilhado em relações dentro e fora de suas comunidades de origem. Essas comunidades ou populações tradicionais podem ser entendidas como

\begin{abstract}
...grupos que conquistaram ou estão lutando por conquistar (prática ou simbolicamente) uma identidade pública conservacionista que inclui algumas das seguintes características: uso de técnicas ambientais de baixo impacto, formas equitativas de organização social, presença de instituições com legitimidade para fazer cumprir suas leis, liderança local e, por fim, traços culturais que são seletivamente reafirmados e reelaborados. (Carneiro da Cunha \& Almeida, 2009, p. 300).
\end{abstract}

Em termos institucionais, a definição de povos e comunidades tradicionais aparece no art. $3^{\circ}$ do Decreto n. ${ }^{\circ} 6.040$, de 7 de fevereiro de 2007 (p. 316):

I - Povos e Comunidades Tradicionais: grupos culturalmente diferenciados e que se reconhecem como tais, que possuem formas próprias de organização social, que ocupam e usam territórios e recursos naturais como condição para sua reprodução cultural, social, religiosa, ancestral e econômica, utilizando conhecimentos, inovações e práticas gerados e transmitidos pela tradição. 
No caso do Brasil podemos citar como exemplos de populações tradicionais: quilombolas, catingueiros, raizeiros, geraizeiros, veredeiros, ribeirinhos, faxinalenses, entre outros, que desempenham atividades agrícolas, pastoris, artesanais, de caça, extrativismo, etc. (Argueta, 2015; CIMOS/MPMG, 2016).

Denominar certo discurso de tradicional também carrega algumas dificuldades. Em primeiro lugar, temos consciência que há todo um acúmulo de debates e controvérsias acerca dos direitos intelectuais de determinados conhecimentos tradicionais, inclusive com legislação nacional e acordos internacionais sobre o tema (Carneiro da Cunha \& Almeida, 2009; Carneiro da Cunha, 2009). Mas, no nosso caso, tratamos o conhecimento tradicional mais como adjetivo do que como substantivo. Ou seja, estamos mais preocupados em caracterizar e discutir o conhecimento no que se refere a diferenças, contrastes e comparações do que abordar sua autoria, mecanismos de compartilhamento e implicações legais fora da comunidade. Em segundo lugar, diferentemente do conhecimento científico que contou com processos de unificação, generalização e universalização para sua justificação ideológica, o conhecimento tradicional, ou melhor, os conhecimentos tradicionais são múltiplos, tão diversos quanto suas comunidades que os (re)produzem.

No conhecimento científico, em contraste [com o conhecimento tradicional], acabaram por imperar definitivamente unidades conceituais. A ciência moderna hegemônica usa conceitos, a ciência tradicional usa percepções. É a lógica do conceito em contraste com a lógica das qualidades sensíveis. Enquanto a primeira levou a grandes conquistas tecnológicas e científicas, a lógica das percepções, do sensível, também levou, afirma Lévi-Strauss, a descobertas e invenções notáveis e a associações cujo fundamento ainda talvez não entendamos completamente. (Carneiro da Cunha, 2009, p. 303-304).

Admitir este contraste não implica ignorar a complexa interação entre os conhecimentos científico e tradicional, às vezes cooperativa, às vezes conflituosa, na sociedade contemporânea (Canclini, 2009). Nos encontros e desencontros interculturais, na globalização de cima para baixo e na de baixo para cima, na luta cotidiana por afirmação e negação de direitos: a vida concreta da produção e reprodução de conhecimentos é povoada por interseções, interpenetrações, imbricamentos, conexões, dissenções, paralelismos, etc. Só para ficarmos em alguns exemplos: o smartphone pode ser artefato tecnológico da cidade ou do campo; é provável encontrarmos uma feira 
livre de pequenos produtores comercializando itens contaminados por agrotóxicos e um hipermercado com gôndolas para alimentos sem veneno; cosmologias indígenas são apresentadas em um museu de ciências; a medicina tradicional torna-se mais visível por meio de redes sociais; o conhecimento das populações tradicionais e indígenas é objeto de apropriação acadêmica (e o movimento inverso, o conhecimento científico é apropriado, também requisitado como direito, por essas comunidades).

Diante dos apontamentos até agora desenvolvidos, uma questão surge, especialmente para os educadores preocupados numa perspectiva intercultural com os conteúdos dos processos de ensinar, os conhecimentos tradicionais podem ser convergentes, divergentes ou paralelos em relação aos científicos (escolares)?

Uma resposta à questão enunciada anteriormente é inspirada na reflexão de Argueta (2015) sobre a construção de uma epistemologia das etnociências e uma agenda para o programa do Sistema de Saberes Indígenas. Segundo esse autor, ao postularmos a convergência dos conhecimentos corremos o risco da articulação utilitária, instrumental e subordinada (até mesmo subsumida) do tradicional ao científico. Enquanto na divergência, não há articulação, tampouco diálogo intercultural e nesse caso predomina o isolamento e fechamento. Por fim, para uma articulação não subordinada, menos assimétrica e dialógica é necessário assumirmos uma posição de saberes paralelos com possibilidades de complementariedade.

O diálogo de saberes nessa perspectiva tem uma utilidade específica e obteria grandes contribuições, pois se almeja que os Sistemas de Saberes Indígenas [aqui estendemos aos conhecimentos tradicionais] estabeleçam pontos de articulação e comparabilidade no diálogo universal de saberes; que se coloquem os desafios de construção de uma tradição; que se estruturem como poder para a tomada de decisões que os afetam; ... é inadiável a tarefa de construir-se como conhecimentos explícitos, que se conhecem o poder de seu saber e o expressem frente a outros saberes. (Argueta, 2015, p. 191, grifo nosso).

\section{Pontos de contato e afastamento entre os conhecimentos tradicional e científico sobre a Lua}

Esta seção possui um título de difícil escolha. Pretendemos discorrer sobre conhecimentos científicos já canonizados e trabalhos acadêmicos que articulam a influência da Lua sobre a vida no/do campo. Ao enunciarmos a expressão pontos de contato e afastamento entre os conhecimentos queremos afirmar um 
processo mais que epistemológico, não restrito às formas de conhecer, mas também sociocultural e contextual. Isso significa que esses pontos não são definidos apenas pela relação dos conhecimentos em si e seus objetos de referência; pelo contrário, são também dependentes dos seus sujeitos e das condições de sua produção e reprodução.

É corriqueiro em uma aula de ciências, ao discutirmos a influência da Lua no ambiente terrestre, sermos conduzidos a discutir suas fases, seus eclipses e órbita em torno da Terra e as marés do ponto de vista dos fenômenos físicos e biológicos (movimentos, forças, fotossíntese, alimentação e reprodução de algumas espécies, etc.). Contudo, somos também defrontados sobre a influência da Lua no nascimento de bebês, no corte de cabelo ou interferências no ciclo menstrual, dentre outros. Algumas dessas questões têm o potencial de exibir pontos de contato e até mesmo de afastamento completo entre conhecimentos científico e tradicional.

Antes de expormos nosso fio principal, é importante deixar claro, categoricamente, que a Lua, enquanto artefato cultural (da ciência, da arte, da tradição, da literatura, etc.), tem inquestionável influência no ambiente e vida terrestre do ponto de vista de qualquer conhecimento. Isso parece óbvio, mas em nome da monocultura da ciência moderna vários sentidos da experiência humana sobre a Lua são silenciados.

Há uma tendência de orientação mecanicista entre professores de ciências que atribui à explicação da influência lunar quase exclusivamente a fenômenos físicos. As forças e os campos gravitacionais somados à explicação da reflexão da luz solar na Lua seriam a explicação científica para a influência da Lua na Terra (os movimentos, as marés e as fases da Lua). De fato, se reduzirmos essa influência a uma relação de causa e efeito restrita a algumas variáveis e independente do entendimento da Lua enquanto artefato cultural, podemos até contentar-nos com essa explicação. No entanto, mesmo do ponto de vista das ciências, a influência da Lua não para por aí, isto é, as marés ou as fases da Lua podem ser consideradas apenas como um ponto de partida.

Somente para termos dimensão da extensão da influência da Lua, podemos considerar trabalhos no âmbito acadêmico que apontam a mudança do comportamento de algumas espécies de roedores, cuícas, gambás (evitam a Lua cheia, pois a intensidade luminosa pode facilitar sua captura por predadores e, portanto, aumentam sua atividade na Lua nova) ou como no morcego-pescador (que 
orienta sua pesca pelo deslocamento dos cardumes de peixes conforme a variação das marés) ${ }^{\mathrm{v}}$ (Bueno \& Motta Júnior, 2005; Bordignon, 2006). E se levarmos em consideração atividades humanas como a pesca (o horário da maré influencia a atividade dos pescadores), o turismo (a maré alta pode encobrir uma praia ou a baixa pode revelar corais e criar piscinas naturais) e a navegação (a Marinha disponibiliza, na internet, a tábua das marés para vários portos e ilhas do litoral brasileiro). ${ }^{\text {vi }}$

Em pesquisa na Revista Brasileira de Agroecologia encontramos seis trabalhos que tratam da influência da Lua no campo, especialmente em relação a plantações. $\mathrm{O}$ primeiro faz o levantamento dos conhecimentos, de tipo de concepções prévias, entre alunos dos cursos superiores de Engenharia Agrícola e Viticultura e Enologia de duas instituições federais do Estado do Rio Grande do Sul. Schiedeck, Cardoso e Schwengber (2007), autores do trabalho mencionado, identificaram que os saberes relacionados à Lua são os mais presentes entre os alunos entrevistados. Dentre esses conhecimentos os autores destacam: i) a poda da videira deve ser feita na Lua minguante; ii) os vegetais que dão embaixo da terra devem ser semeados na Lua minguante; iii) quando há chuva até o quinto dia da Lua nova, chove em todas mudanças de Lua até o fim do ciclo.

Do ponto de vista empírico, Menin et al. (2014) desenvolveram experimento para analisar a influência das fases lunares no desenvolvimento das culturas de rúcula. Os autores observaram que,

na cultura da rúcula a fase da Lua crescente influenciou significativamente no número $\mathrm{e}$ largura de folhas, no entanto as fases lunares não foram significativas quanto ao desenvolvimento de massa verde. Para o rabanete, a fase lunar quarto crescente mostrou-se superior para a principal variável avaliada, o peso fresco de raízes, no entanto, também apresentou maior percentual de raízes rachadas e isoporizadas. (Menin et al., 2014, p. 122).

Jovchelevich e Câmara (2008) conduziram trabalho para investigar a influência da Lua sobre o rendimento da cenoura $^{\text {vii }}$. Os autores realizaram duas semeaduras em dois anos consecutivos e, segundo eles, observaram diferença significativa (5\%) na variável massa seca de raízes, para as quais a semeadura na Lua nova apresenta o maior resultado.

Em direção semelhante à do trabalho anterior, Oliveira, Freitas e Rafael (2009a) avaliaram o efeito do impulso ascendente e descendente lunar sobre a emergência de plântulas de murici e observaram que o percentual de emergência das sementes plantadas no período ascendente (quando a 
Lua se aproxima da terra) foi consideravelmente maior $(10 \%)$ que o daquelas semeadas no período descendente. ${ }^{\text {viii }}$

Ainda na direção dos trabalhos experimentais, Oliveira, Freitas e Rafael (2009b) conduziram experimento com duas variedades de espécies ornamentais e, a partir do seu trabalho, chegaram à conclusão de que as fases da Lua não influenciam no enraizamento do manacá de cheiro e no gengibre azul, mas que seriam necessários outros estudos nessa direção.

A nosso ver, os trabalhos orientados pelo propósito mais restrito da busca por resultados empíricos na direção de reforçar que há influência lunar nas plantações possuem fragilidades do ponto de vista da ciência ocidental stricto sensu, bem como lacunas e certa incongruência do ponto de vista epistemológico. Em primeiro lugar, a capacidade de generalização (pela ótica da ciência) dos experimentos desenvolvidos é mínima, senão questionável: em alguns casos, a diferença dos dados é pequena e, em outros, existem tantas variáveis envolvidas no processo (solo, iluminação noturna e diurna, temperatura, umidade, dentre outras) que isolar apenas uma delas não inspira uma razoável validade e confiabilidade, considerando uma comunidade acadêmica ou científica (como dissemos, no sentido restrito de ciência).
Em segundo lugar, o pecado original, por assim dizer, dessa perspectiva de experimentos consiste em tratar o conhecimento tradicional e os fenômenos por ele explicados pelos óculos exclusivos da ciência ocidental.

Outros pesquisadores, contudo, mesmo dentro da ciência canônica têm considerado, embora em menor medida, hipóteses com relação à influência lunar sobre as plantas, como Raven, Evert e Eichhorn (2007), autores de um dos clássicos na área da botânica. Para eles, não apenas o comprimento dos dias e das noites influenciam os mecanismos vegetais como também a luz da lua pode ser uma das explicações para o comportamento de movimentos foliares em algumas espécies para impedir a absorção de luz em noites claras de modo a preservar os ritmos da planta em relação a seu metabolismo. É o início muito pequeno de um diálogo com outros conhecimentos já constatados pelos povos tradicionais, mas estima-se que seja frequente. Diante disso, acreditamos que trabalhos dentro do espectro das chamadas etnociências, e também da antropologia e educação, podem oferecer aportes que fortaleçam o caminho traçado nessa pesquisa.

Marques et al. (2007) elaboraram calendário lunar agrícola a partir da coleta de informações e diálogo com a 
comunidade indígena Tupinambá da Serra do Padeiro em Ilhéus-BA. Segundo os autores, destacam-se as seguintes práticas culturais orientadas pelo ciclo lunar:

Lua nova recomendada para: castrar animais, o porco castrado nesta fase lunar fica com o toucinho fino e mole; plantar cacau, pois cresce rápido e dá bons frutos; ...; plantar maniva, a planta cresce, engrossa as raízes e evita pragas e doenças; .... A Lua crescente, segundo o diagnóstico, não é recomendada para o plantio de hortaliças, que crescem apenas os talos, nem plantas cujo objetivo é a raiz, pois as folhas crescem muito e as raízes não; .... Na Lua cheia, efetua-se o plantio de banana-da-terra; ... colhe-se a embira na mata, para fabricação de tangas, e não se pode plantar milho, feijão e outros plantios de grãos, .... A Lua minguante é um bom período para podar árvores e para colheita de "tronco" (pseudocaule), de bananeira para fibra de artesanato. (Marques et al., 2007, p. 565).

Mello, Soares e Kerber (2009) assumem a tese do ensino da astronomia cultural a partir das suas experiências no ensino de astronomia e ciências naturais em cursos de formação de professores indígenas. Os autores discutem elementos do sistema cosmológico Guarani em diálogo com o pensamento científico ocidental, o que só é possível sob uma perspectiva intercultural e transdisciplinar. Nesse sentido, um passo epistemológico/intercultural necessário é reconhecer que os objetos astronômicos, notadamente o céu, as estrelas, o Sol, a Lua, eclipses, etc. estão inseridos num entendimento mais totalizante e holístico para essa comunidade: eles são indissociáveis da vida e dos fenômenos que acontecem na terra.

... Sol e Lua indicam regras de relações sociais, marcação de ciclos humanos e passagens de fases da vida social, como nascimento, morte (e vida pós-morte), puberdade (marcada pela menstruação nas mulheres e mudança da voz nos homens), maturidade, etc., relações com o meio ambiente, calendários agrícolas. Enfim, as relações entre os humanos e o Sol e a Lua, informa diferentes aspectos da vida humana. (Mello, Soares \& Kerber, 2009, p. 8).

No mesmo caminho, Garcia et al. (2016) realizaram levantamentos por meio de oficina pedagógica do conhecimento etnoastronômico em torno de temas como a criação do Sol e da Lua, as fases da Lua, as estações do ano e as estrelas de uma comunidade indígena do norte do Rio Grande do Sul com o objetivo de construir um material paradidático para a escola local. Para os autores, esse processo foi uma contribuição inicial para "revivificação" dos conhecimentos locais, além de permitir sua inserção no ambiente escolar sem que haja sobreposição, desmerecimento ou descaracterização por parte do conhecimento científico. Cabe destacar que a estratégia empregada pelos 
autores foi a de elaborar o material paradidático abordando exclusivamente o conhecimento da comunidade indígena. Essa é uma das questões que tensionam o ensino intercultural: de que modo e em que medida se dá o processo de visibilidade e reconhecimento das diferentes culturas e quais propostas pedagógicas ou didáticas para promoção da educação intercultural?

A dissertação de mestrado de Almeida (2005), "Do tempo da terra comum ao espremimento: estudo sobre a lógica e o saber camponês na Baixada Cuiabana" oferece elementos fundamentais para compreensão do processo de produção e reprodução do conhecimento de uma comunidade camponesa. O autor realiza trabalho etnográfico numa região que passou por quase um século marcado pelo uso comum de terras até a entrada de uma fazenda criadora de gado na década de 1970, o que deu início a um período de conflitos e perda de território. Apesar disso, segundo o autor, a comunidade ainda mantém e valoriza seu saber e quando preciso incorpora outros conhecimentos que venham a trazer melhoras na sua prática produtiva.

Almeida (2005) discute em seu trabalho o sistema Lua observado na comunidade objeto da sua investigação. Por trás desse sistema há um modelo governado por princípios de equilíbrio, harmonia e reciprocidade. Por exemplo, uma planta considerada fraca deve ser plantada numa lua forte para "poder equilibrar". Nesse sistema Lua, existem dois períodos de 15 dias cada: o crescente (Lua forte), que se inicia um dia após a Lua nova e o minguante (Lua fraca), que se inicia um dia após a Lua cheia.

\begin{abstract}
... o que é de haste (arroz, milho e rama) ou de madeira (árvores, pés de frutas) é considerado forte, porque sobem ou, porque crescem; enquanto cipó (melancia, amendoim, feijão, abóbora), e raiz (batata doce e cará) é considerado fraco, porque ficam no chão ou porque latam. Assim, o equilíbrio é procurado na relação ideal onde o que é mais forte planta na lua fraca e o que é mais fraco planta na lua forte, para compensar. Ou seja, a relação ideologicamente correta é a que busca equilibrar o forte com o fraco para não carregar muito numa característica, o que traria como consequência uma perda muito grande em outra característica igualmente desejada, o que poderia ser potencialmente desastroso. (Almeida, 2005, p. 70, grifos do autor).
\end{abstract}

\section{A lua na vida no/do campo: produções escritas dos licenciandos do campo}

O curso de Licenciatura em Educação do Campo da UFTM, ao qual nossos sujeitos de pesquisa estão vinculados, é um dos quarenta e dois cursos criados a partir do Edital SESU/SETEC/SECADI $n^{\circ}$ 02/2012, com habilitações nas áreas de Matemática e Ciências da Natureza. Em julho de 2014 
sua primeira turma foi aberta e, em seguida, nos meses de janeiro e julho de 2015, outras duas novas turmas de licenciandos do campo foram criadas. Os dados coletados foram produzidos por essa última turma, formada por estudantes das regiões do Triângulo Mineiro, Norte e Noroeste de Minas e também um aluno do estado de Rondônia e outra aluna do estado da Bahia.

O curso assume a Pedagogia da Alternância com momentos de estudo intensivo na universidade chamados de períodos de Tempo Escola (TE), durante os meses de janeiro, julho e uma semana do mês de outubro; entre esses meses ocorrem os períodos denominados Tempo Comunidade (TC), nos quais os alunos permanecem em suas comunidades de origem enquanto realizam algumas tarefas escolares orientadas à distância e em alguns momentos de forma presencial sob a supervisão de professores do curso.

Uma das disciplinas do projeto pedagógico do curso denomina-se Introdução à Física, comum às duas habilitações, com carga horária total de 75 horas-aula, tendo como uma de suas metas a aprendizagem de conceitos básicos de astronomia. Assim, a temática da Lua emergiu de uma proposta de trabalho final dessa disciplina do curso mencionado que tinha como objetivo a pesquisa sobre o modo como os conhecimentos científico e tradicional estão relacionados à Lua e as suas implicações para o Ensino de Ciências.

Uma das dinâmicas que adotamos no curso quando se trata da confecção de trabalhos finais ou sínteses de disciplinas é o momento de "retorno", à distância ou presencial, que tem como objetivo aprofundar as reflexões dos licenciandos até então esboçadas nos trabalhos, orientar quanto à escrita de tipo acadêmica (modo de formatação, organização das citações, referências, etc.) e também indicar fontes e métodos de coletas de dados (documentos, livros, artigos, entrevistas, questionários, etc.). Foi o que ocorreu com o trabalho objeto de nossa análise. De julho a outubro de 2016 os licenciandos elaboraram uma primeira versão do trabalho e de outubro a dezembro do mesmo ano produziram sua versão final.

A disciplina foi ofertada para duas turmas: a de matemática com treze e a de ciências da natureza com trinta licenciandos. Nessa exposição abrimos mão de uma categorização de tipo esquemática do conjunto das produções escritas a fim de dar maior ênfase a enunciados mais representativos de alguns sujeitos, com o objetivo de deixar mais claro os sentidos que circularam nas produções escritas. Destacaremos algumas 
passagens das produções escritas dos professores em formação com o objetivo de tornar visível o conhecimento tradicional nas práticas sociais atuais de comunidades do campo e justificar sua importância para o ensino intercultural de ciências. De modo mais específico, privilegiaremos trechos transcritos ou parafraseados, pelos licenciandos, de membros de suas comunidades do campo.

Houve um predomínio de relatos e trechos que tratavam da relação do plantio e colheita com as fases da Lua. Evidentemente, a proximidade do trabalho e da vida no campo favorece a abordagem dessa relação em especial. Procuramos selecionar passagens de licenciandos de mais de uma localidade. Todos os nomes dos sujeitos entrevistados, bem como os dos licenciandos do campo, foram alterados a fim de se preservar suas identidades.

Para a senhora D. Lúcia Alves dos Santos os plantios devem ser na lua crescente, pois o plantio das plantas acompanha o crescimento da lua. Ela chegou a usar a expressão "plantar na lua fina", pois esta vai crescendo e influenciando no crescimento das plantas. Já o senhor Benedito de Almeida foi mais categórico. Ele afirma que o que fica fora da terra é plantado na nova e crescente, tipo frutíferas, feijão e outros tipos. Mas mandioca e outros que vão de baixo da terra, tem que se plantar na minguante, pois enquanto mingua se o que está fora da terra cresce o que está submerso. (Tomás, licenciando da região do Triângulo Mineiro).

Eu planto [depoimento de Marcelina Souza, moradora de comunidade do campo] minhas mudas de mandioca sempre na fase da lua minguante pelo fato da produção final ser bem melhor, raiz cresce bastante $\mathrm{e}$ engrossa, fazendo que a coleta tenha mais qualidade e menos praga, ao levar a mandioca pra minha pequena fábrica, percebi que ao fazer o polvilho na época contrária ao plantio, na fase da Lua crescente, uma prensa de massa ao final do processo, deu vinte pratos de polvilho, e nessa mesma prensa, mas na fase da Lua minguante, ocorreu uma queda de quatro pratos em relação à fase da Lua crescente, com a produção chegando apenas a dezesseis pratos de polvilho. (Fernando, licenciando da região do Norte de Minas Gerais).

No plantio da cana, quando se planta na minguante ela pode até crescer e produzir menos, mas está menos propicia ao ataque de algumas pragas, se plantada em outras fases da lua ela pode até produzir mais cana, ficar mais viçosa, mas esta susceptível ao ataque de pragas e outras doenças que atacam a cana. (Lucas, licenciando do estado de Rondônia).

Em primeiro lugar, tanto pela pesquisa bibliográfica realizada quanto através das informações obtidas, percebese que a influência da Lua sobre as plantações não é determinada em si pelo dia exato que corresponde às quatro fases da Lua: nova, quarto crescente, cheia e quarto minguante. É como se existissem basicamente dois períodos: um no qual a 
Lua cresce, do dia em que inicia ou um dia após a Lua Nova, passando pelo quarto crescente até o dia de Lua Cheia; e outro no qual a Lua mingua, do dia em que inicia ou um dia após a Lua Cheia, passando pelo quarto minguante, até a Lua Nova. Aquilo que cresce para baixo da terra é favorecido pelo período que a Lua mingua e aquilo que cresce para cima é favorecido pelo período que a Lua cresce.

Esses dois períodos também influenciam a maior ou menor presença de pragas e produtividade do que foi plantado ou do que será posteriormente manipulado: o período da Lua que mingua é menos propício à propagação de pragas e contribui para a produtividade (engrossamento) da mandioca; e o da Lua que cresce favorece a produtividade (produção de polvilho) e também o desenvolvimento da cana, mas com a limitação de que essa última será mais suscetível a pragas.

Outra relação frequentemente relatada pelos licenciandos é a castração de animais e os períodos em que a Lua mingua ou cresce. Nesse caso, como no plantio, o período no qual a Lua mingua é mais propício para castração, pois "há menos micróbios no ar", evitando-se a inflamação e garantindo uma boa cicatrização. A melhor época para o corte de madeira também é o período que a Lua mingua, do contrário a madeira apodrece mais facilmente e fica sujeita à infestação de carunchos e cupins.

Senhor Benedito enfatizou também a influência da lua na castração de animais e no corte de madeira. A castração para cicatrizar mais rápido e evitar inflamação no animal deve ser feita na lua minguante; também porque o animal se desenvolve de forma igual nas partes traseiras e dianteiras, ocorrendo a castração durante a influência de fase da lua que não seja a minguante, o animal desenvolve somente a parte traseira e fica aniquilada na parte dianteira. Senhor Nicolau disse que na fase da lua minguante há menos micróbios no ar e por isso os cupins não atacam madeira verdes cortadas nesses dias de influência da lua minguante. (Tomás, licenciando da região do Triângulo Mineiro).

... quando eu [depoimento de Álvaro Dias, morador de comunidade do campo] vou cortar madeira para construção de casa de roda, ripas ou caibros, a fase da lua tem que ser a minguante, pois, meu pai já dizia que nessa época a madeira absorve menor quantidade de água do solo. Nas outras luas, ela fica mais encharcada e o mourão apodrece com mais facilidade. (Júlia, licencianda da região Norte de Minas).

Com apenas um relato, possivelmente porque nas comunidades dos licenciandos essa atividade tem menor peso, a prática da pesca e sua relação com as diferentes fases da Lua foi lembrada. Aqui, a Lua Cheia é a que contribui para uma boa pesca. 
Observo [depoimento de Alexandre, 86 anos, morador de comunidade do campo] bastante em que fase da Lua está porque ela influencia muito na pescaria, sempre vou pescar na Lua Cheia, dá muito peixe. Já na Lua minguante, não dá quase nada, não adianta nem ir porque se não vou passar é raiva. (Amanda, licencianda da região Norte de Minas).

Outro aspecto observado nas produções escritas é a manifestação nas falas dos sujeitos entrevistados ou nas suas paráfrases empreendidas pelos licenciandos do campo de um debate de ordem epistemológica que chamaremos de questão verdade versus verossimilhança. $\mathrm{O}$ conhecimento científico preza pela verdade absoluta no sentido paradigmático, enquanto $o$ conhecimento tradicional precisa ser verossímil: é mais tolerante; aceita diferentes explicações porque sua validade é local; e, a experimentação a que está submetido opera pela "lógica das percepções” (Carneiro da Cunha, 2009).

[Depoimento de Joaquim de Souza, morador de comunidade do campo]: uso, os saberes da lua, para ter boa produção na lavoura de mandioca e em meu pomar. Mas para ter chegado a tais conclusões em que te falo, passamos por vários prejuízos, pois era teimoso e duvidava desses saberes que meu pai me ensinava desde criança, quis fazer experimentos em minhas plantações e só levei prejuízo, por isso aconselho a seguir aos saberes passados pelos experientes. Hoje já estou velho. Ensino para os jovens que tem dúvidas, falo e garanto que há diferença na lavoura de acordo com a lua de plantio. E, os jovens têm confiança em minhas palavras. Pois veem minhas plantações e perguntam quais são os segredos. Digo sempre: as luas cheia e minguante são as melhores para plantar, pois ao plantar nesse período as raízes crescem mais do que nas outras luas dando rendimento na hora da colheita. Já na lua crescente, as plantas crescem mais rápido, mas não é indicado plantar, pelo fato dos insetos atacarem com mais frequência a plantação. Nas fases seguintes a plantação já estará com o broto e os insetos atacarão. Por isso não é indicado! Sendo uma das piores luas para plantar a lua crescente. Motivo de não se plantar nessa fase? Pelo fato do prejuízo ser maior. (Ana, licencianda da região do Norte de Minas).

Além do mencionado, o conhecimento tradicional e as práticas sociais associadas a ele só podem ser compreendidos de forma orgânica e inseparável porque o conhecimento tradicional é resultado, por assim dizer, da fusão de várias dimensões (do trabalho, da cultura, da fé, enfim, da vida) que compõem a visão de mundo do sujeito. [Depoimento de Maria de Jesus,
moradora comunidade do campo]: O
ato de acreditar dar a sensação de que
realmente acontece, mas quem faz
todas as coisas é Deus, inclusive a
criação da lua precisávamos ter
alguma coisa de referência para o
plantio e várias outras coisas e
utilizamos a lua, que um sinal de
Deus. Da mesma forma que Deus
tinha os discípulos para ajudá-lo na
propagação do evangelho, ele criou a
lua para ajudar os trabalhadores. 
(Elen, licencianda da região do Norte de Minas).

\section{Considerações finais}

Observamos em parte considerável dos trabalhos objeto do levantamento bibliográfico realizado contribuições que, caso fossem dialogadas, compartilhadas e assumidas como de tipo experimental (ou daqueles restritos ao mapeamento de conhecimentos), teriam potencial para conduzir novas propostas de práticas pedagógicas interculturais, além de aprofundar a reflexão teórica dos diferentes campos que tratam do reconhecimento do conhecimento tradicional.

Assumindo o pressuposto do ensino intercultural de ciências, assim como o diálogo de saberes nos processos formativos de educadores do campo, admitimos que é preciso inserir o conhecimento tradicional no currículo de ciências a partir de estratégias que demarquem as fronteiras e os contextos de uso entre o tradicional e o científico e que por meio de seus pontos de contato, interculturalmente, estimule o intercâmbio e o enriquecimento mútuo.

Terminamos o texto com trecho de uma das produções escritas que reflete as implicações nos sujeitos da Licenciatura em Educação do Campo quando o conhecimento tradicional passa a ser objeto legítimo e reconhecido de um trabalho de conclusão de uma disciplina da universidade. Nas considerações finais do trabalho de Fernando, licenciando da região Norte de Minas Gerais:

\begin{abstract}
Percebe que o saber científico não traz muita contradição com o popular, mas o saber popular é rico em informações de técnicas agrícolas adquiridas durante suas experiências de vida, todas as suas informações são armazenadas em suas mentes. São verdadeiros exemplos de conhecimento, memórias fantásticas, por explicar seus saberes com total clareza e certeza em suas palavras. Mas o científico traz mais certeza e dá mais confiança ao leitor por ter mais expressão e é mais divulgado do que o popular que é mais um conhecimento próprio adquirido por cada cidadão .... Encerro essa pesquisa priorizando o saber popular em suas diversas áreas, por ser um conhecimento adquirido sem o acesso a livro, escola e muito menos cursos superiores, e por ter a consciência que o saber científico é muito bom, mas com essa ausência que tem as famílias rurais ao passar do tempo eles transformaram o saber popular em afirmações na sua maioria como certezas concretas.
\end{abstract}

\section{Referências}

Aikenhead, G. S. (2009). Educação científica para todos. Lisboa, PT: Edições Pedago.

Almeida, R. A. (2005). Do tempo da terra comum ao espremimento: estudo sobre a lógica e o saber camponês na baixada cuiabana (Dissertação de Mestrado). Universidade de Brasília, Brasília. 
Antunes-Rocha, M. I. (2009). Licenciatura em educação do campo: histórico e projeto político-pedagógico. In Antunes-Rocha, M. I. \& Martins, A. A. (Orgs.). Educação do Campo: desafios para formação de professores. Belo Horizonte, MG: Autêntica Editora.

Argueta, A. (2015). Os saberes e as práticas tradicionais: conceitos e propostas para a construção de um campo transdisciplinar. In Udry, C., \& Eidt, J. Simoni (Orgs.). Conhecimento tradicional: conceitos e marco legal. Brasília, DF: Embrapa.

Arroyo, M. G. (2008). Os coletivos diversos repolitizam a formação. In DinizPereira, J. E. \& Leão, G. (Orgs.). Quando a diversidade interroga a formação docente. Belo Horizonte, MG: Autêntica Editora.

Arroyo, M. G. (2011). Currículo, território em disputa. Petrópolis, RJ: Editora Vozes.

Bakhtin, M. (2010). Problemas da poética de Dostoiévski. Rio de Janeiro, RJ: Forense Universitária.

Bordignon, M. O. (2006). Padrão de atividade e comportamento do comportamento de forrageamento do morcego-pescador Noctilio leporinus (Linnaeus) (Chiroptera, Noctilionidae) na Baía de Guaratuba, Paraná, Brasil. Revista Brasileira de Zoologia, 23(1), 50-57.

Brick, E., Pernambuco, M. M. C. A., Silva, Antônio F. G., \& Delizoicov, D. (2014). Paulo Freire: interfaces entre Ensino de Ciências Naturais e Educação do Campo. In Molina, M. C. (Org.). Licenciaturas em Educação do Campo e o ensino de Ciências Naturais: desafios à promoção do trabalho docente interdisciplinar. Brasília, DF: MDA.

Bueno, A., \& Motta Júnior, J. C. (2005). A Lua $\mathrm{e}$ os pequenos mamíferos: comportamento de certos roedores pode mudar em noites de Lua cheia. Revista Ciência Hoje, 37(219), 64-66.

Candau, V. M. (2013). Interculturalidade e educação escolar. In Candau, V. M. (Org.), Reinventar a escola (pp. 47-60). Petrópolis, RJ: Vozes.

Canclini, N. G. (2003). Culturas Híbridas: Estratégias para entrar e sair da modernidade. São Paulo, SP: Editora da Universidade de São Paulo.

Carneiro da Cunha, M., \& Almeida, M. W. B. (2009). Populações tradicionais e conservação ambiental. In Carneiro da Cunha, M. (org.). Cultura com aspas. São Paulo, SP: Cosac Naify.

Carneiro da Cunha, M. (2009). Relações e dissensões entre saberes tradicionais e saber científico. __ In Carneiro da Cunha, M. (org.). Cultura com aspas. São Paulo, SP: Cosac Naify.

Decreto Lei $\mathrm{n}^{\circ}$ 6.040/2007. (2007). Institui a Política Nacional de Desenvolvimento Sustentável dos Povos e Comunidades Tradicionais. Recuperado de: http://www.planalto.gov.br/ccivil_03/_ato2 007-2010/2007/decreto/d6040.htm

Foroni, Y. M. A. (2004). A perspectiva intercultural na formação de professores. Revista Puc Viva. São Paulo, 21, 81-89.

Fleuri, R. M. (2003). Educação Intercultural: mediações necessárias. Rio de Janeiro, RJ: DP\&A.

Flores, V., Barbisan, L. B., Finatto, M. J. B. \& Teixeira, M. (2009). Dicionário de Linguística da Enunciação. São Paulo, SP: Contexto.

Garcia, C. S., Costa, S., Pascoali, S., \& Campos, M. Z. C. (2016). "As coisas do céu": etnoastronomia de uma comunidade indígena como subsídio para a proposta de 
um material paradidático. Revista LatinoAmericana de Educação em Astronomia (RELEA), 21, 7-30.

Jovchelevich, P., \& Câmara, F. L. A. (2008). Influência dos ritmos lunares sobre o rendimento de cenoura (Daucus carrotta), em cultivo biodinâmico. Revista Brasileira de Agroecologia, 3(1), 49-57.

Marques, C. T. S., Gama, E. V. S., Carvalho, A. J. A., Silva, F., \& Frias, M. T. (2007). Influência lunar nas práticas agrícolas da Aldeia Indígena Tupinambá de Serra do Padeiro, Buerarema - BA. Revista Brasileira de Agroecologia, 2(2), 563-566.

Mello, F. C., Soares, J. B., \& Kerber, L. (2011). Astronomia e educação intercultural: experiências no ensino de astronomia e ciências em escolas indígenas. In I Simpósio Nacional de Educação em Astronomia (I SNEA). Rio de Janeiro, RJ: Anais do I SNEA.

Menin, L. F., Rambo, J. R., Frasson, D. B., Pereira, T. A. X., \& Santi, A. (2014). Influência das fases lunares no desenvolvimento das culturas de rúcula (Erucasativa Hill) e rabanete (Raphanus sativus L.). Revista Brasileira de Agroecologia, 9(3), 117-123.

Oliveira, R. T., Freitas, J. B. S., \& Rafael, M. S. S. (2009a). Influência do impulso de ascendência e descendência lunar e do tamanho da semente na emergência de plântulas murici. Revista Brasileira de Agroecologia, 4(2).

Oliveira, M. C., Ottmann, M. M. A., Da Cruz, M. R., Leal, L., \& Ferriani, A. P. (2009b). Influência das fases da Lua no enraizamento de estacas de Dichorisandra Thyrsiflora Mik (Gengibre-Azul) e Brunfelsia Uniflora (Pohl.) D. Don. (manacá-de-cheiro) na primavera. Revista Brasileira de Agroecologia, 4(2).
Paladino, M., \& Almeida, N. P. (2012). Diversidade e interculturalidade. In Paladino, M., \& Almeida, N. P. Entre a diversidade e a desigualdade: uma análise das políticas públicas para a educação escolar indígena no Brasil dos governos Lula. Rio de Janeiro, RJ: Contra Capa Livraria; LACED/Museu Nacional/UFRJ.

Santos, B. S. (2003). Por uma concepção multicultural de direitos humanos. In Santos, B. S. (Org.). Reconhecer para libertar: os caminhos do cosmopolitismo multicultural. Rio de Janeiro, RJ: Civilização Brasileira, 2003.

Santos, B. S. (2009). Para além do pensamento abissal: das linhas globais a uma ecologia de saberes. In Santos, B. S., \& Meneses, M. P. (Orgs.). Epistemologias do Sul. Coimbra, PT: Almedina.

Schiedeck, G., Cardoso, J. H., \& Schwengber, J. E. (2007). Saber popular como elemento primordial para trabalhos em Agroecologia. Revista Brasileira de Agroecologia, 2(2).

Raven, P. H., Evert, R. F., \& Eichhorn, S. E. (2007). Biologia Vegetal. Rio de Janeiro, RJ: Gen/Editora Guanabara Koogan.

Walesko, A. M. H. (2006). A Interculturalidade no Ensino Comunicativo de Língua Estrangeira: um estudo em sala de aula com leitura em inglês (Dissertação de Mestrado). Universidade Federal do Paraná, Paraná.

\footnotetext{
i Boaventura de Sousa Santos (2003) faz uma distinção entre os movimentos de globalização de cima para baixo e de baixo para cima. O primeiro identificado com a globalização neoliberal ou hegemônica e o segundo com a globalização solidária ou contra hegemônica.

ii Responsável no sentido bakhtiniano: o que implica, responde, compromete-se dialogicamente a partir e por meio do outro.
} 
iii Evidentemente não desconsideramos as relações entre saberes e conhecimentos, apenas não é nosso objeto neste texto.

iv Recontextualização no sentido empregado por Bernstein (1998), como exemplo, o discurso da ciência que se desloca da sua posição original e constitui-se como discurso da ciência escolar: já não é o mesmo discurso, pois nessa transformação intervém a ideologia.

v Há também estudos sobre o comportamento de coelhos, aves noturnas, abelhas e até serpentes nas mudanças de fase lunar (Bueno \& Motta Júnior, 2005).

vi http://www.mar.mil.br/dhn/chm/box-previsaomare/tabuas/.

vii Esses autores tomam como base referenciais da chamada agricultura biodinâmica. Nela o conhecimento tradicional ou popular é tomado como uma das suas bases, mas não só. Um exemplo é o calendário astronômico biodinâmico que usa como referência a movimentação da Lua através das regiões do zodíaco.

viii Uma versão de divulgação desse trabalho também foi publicada na revista Ciência Hoje com o título Semeando ao Luar, em 31 de maio de 2010.

Recebido em: 25/05/2017

Aprovado em: 19/06/2017

Publicado em: 13/12/2017
Como citar este artigo / How to cite this article / Como citar este artículo:

APA:

Crepalde, R. S., Klepka, V., \& Halley, T. O. P. (2017). Interculturalidade e conhecimento tradicional sobre a Lua na formação de professores no/do campo. Rev. Bras. Educ. Camp., 2(3), 836-860. DOI: http://dx.doi.org/10.20873/uft.25254863.2017v2n3p836

\section{ABNT:}

CREPALDE, R. S., KLEPKA, V.; HALLEY, T. O. P. Interculturalidade e conhecimento tradicional sobre a Lua na formação de professores no/do campo. Rev. Bras. Educ. Camp., Tocantinópolis, v. 2, n. 3, p. 836-860, 2017. DOI: http://dx.doi.org/10.20873/uft.2525$\underline{4863.2017 \mathrm{v} 2 \mathrm{n} 3 \mathrm{p} 836}$

\section{ORCID}

Rodrigo dos Santos Crepalde

https://orcid.org/0000-0001-7025-7010

Verônica Klepka

https://orcid.org/0000-0002-9937-9852

Tânia Halley Oliveira Pinto

D https://orcid.org/0000-0002-1368-4451 